\title{
On Construction of the Characteristic Educational Resources of Ethnic Regions in Gansu, China
}

\author{
Jun Ma \\ School of Educational Science and Technology, Northwest University for Nationalities Lanzhou 730124, \\ P.R. China \\ 364221500@qq.com
}

Keywords: Ethnic regions; Characteristic educational resource; Constructive development

\begin{abstract}
The construction of characteristic educational resource plays a very significant role in social development for ethnic regions in China. This paper investigated the characteristic educational resource taking selected ethnic regions in Gansu province as example. The analysis was conducted by the means of survey and individual interview which was collected in May 2014 in seven ethnic counties. As a typical ethnic region, the characteristic educational resource in Gansu represents the overall situation on educational resources in Gansu province, China. The purpose of this paper is to build the constructive solutions of characteristic educational resource which can be expanded in ethnic regions in China as a whole.
\end{abstract}

\section{Introduction}

The characteristic educational resource in ethnic regions is the important part of the regional development and it is the important foundation to realize the social informationization and national economic development. The long-term education reform and development plan (2010-2020) proposed education information process. Open and flexible educational resources and public service platform can promote the popularization of quality education resources and other major strategic deployment and initiatives. The various educational information resources are one of the main content of educational design theory and practice of teaching resource database, particularly in foreign countries such as Britain and the United States. The educational resource development has formed serious of strict standards and the implementation of management models. Therefore, how to promote the effective construction of characteristic educational resource and sustainable development of the resource base is the biggest challenge for ethnic regions. Therefore, it is urgent to boost the characteristic educational resources in the ethnic regions. At present, the characteristic educational resource is in an exploration stage in the construction of the actual educational resource.

Gansu is an agricultural province with ethnic regions and poor education in Gansu province which provide the place for the hui, han, dongxiang, bao'an, salar, tu, Tibetan and other 22 national more than 200 people of all ethnic groups. The survey is made to Guanghe, Kangle, Jishishang, Yongjin, Linxia, Hezheng and other cities, towns and villages. The survey is divided into principal and teacher questionnaires. The principal survey designed 41 questions, and 24 questions for teachers, covering many aspects of characteristic educational information. This paper also analyzes the current situation of the characteristic educational resources in ethnic regions, the constructive suggestions the put forward to provide the construction of the characteristic educational resources in ethnic regions.

\section{The Necessity of Building the Characteristics of Education Resource}

The construction characteristic education resource entails the library collection and enrich the network resources which is easy to search. As the search engine is not in accordance with the professional division, 
it can not match the semantic content or meet the needs of professional search. According to the service object of the school of professional information, construction of characteristic education resources, development representative characteristics of education resources storehouse, further in-depth search of information collection, information to meet the needs of the region and for readers provide in-depth literature information service.

The construction of digital library information to the key discipline of the school, through characteristic education resources construction of key subjects can work with information network environment. In favor of literature resources sharing resources and on the basis of cooperation established characteristic digital database, and with combination of the National information to achieve complementary advantages. It can maximize the potential and advantages of library. From the overall, the construction of universities for nationalities the literature information resource guarantee system, to meet the needs of teaching and scientific research. From the needs of readers, construction of the Institute of professional characteristics and features collection of characteristic education resources library, it is conducive to the school teachers and students to master the latest science and technology give full play to the advantages of professional to enhance the comprehensive competitiveness.

\section{Construction Principle}

The construction principle of characteristic education resources is very important to improve the quality and the use value of the education resources storehouse. Many papers argued a large space to explain this problem, the main points of view are as follows:

Characteristics of the Collection Principle. The selected topic of the characteristic education resources should be fully reflected the characteristics of the library, which is the fundamental guarantee for the value of the resources of the education resources.

Systematic Principle. In the construction of characteristic education resource library, the comprehensive and systematic information is of great significance. In addition to printing characteristic literature digital outside, but also extensive collection of various other forms of information, after the completion of the building information on the new continuous collection to make the characteristic education resources to use value and vitality.

Feasibility Principle. Construction of characteristic education resources must consider all aspects of the analysis of the established education resources storehouse construction after the completion of the resources rich degree, content system and the complete degree, digital processing technology and the ability, funding, personnel, experience, such as the development cycle, to ensure that the characteristic construction of educational resources base quickly and efficiently.

Sharing Principle. Literature collection standard, data description format, digital transformation, the operating system and the main equipment, such as the needs for good consistency and follow the unified standards and norms, the characteristic education resources is to share the good effect.

The Principle of Regional Characteristics. The regional characteristic literature education resources library should be established, its content in a certain region has its own uniqueness. It can bring on geographical location or other factors collection advantage, mining potential of literature information resources characteristic education resources construction and principle of regional characteristics is conducive to build.

The Practical and the Economic Principle. Building the characteristic education resource is to meet the needs of the literature information, and the utility is an important index to evaluate the value of an educational resource. Database must be in full investigation. We should follow the principle of economy, the choice of platform construction to economical and practical according to the resource type of self education resources base. The educational resources release mode setting equipment of the hardware. 


\section{The Current Situation of the Characteristic Educational Resources in Ethnic Regions}

The Ministry of Education in China developed "technology standards for modern distance education technology engineering of education resource construction", it has caused a boom in the construction of educational resources and researches. Achievements have been made, but there are many problems and solutions. The problems of educational resources in ethnic regions are mainly reflected in the following aspects.

Inaccurate Construction of the Resource Pool. The development of education informationization promotes the rapid development of the construction about characteristic educational resources, however, the construction of educational resources just pays attention to the number, and the utility is not strong, this problem is very common in ethnic regions in Gansu. The main function of the characteristic educational resource is to serve the education. The construction of the project should be based on the actual educational requirement of the school, In order to serve the teachers' educational and students' learning as the goal.

Lacking of Uniform Standards. There is no uniform standard for characteristic resource construction, and the classification is far from standard, and the basic attribute of resource is not accurate enough, So as to lead to the generation of data is land, it also caused the duplication of resources.

Lacking of Unified Management of the Resource Pool Construction. In the construction of the resource pool, the development of the school is not poor, the lack of macro grasp, the developers of most of the resources are independent, the construction of the resources is relatively scattered, there is no unified storage platform, Lacking of effective consolidation and consolidation. The resource construction often does not constitute a whole system. The use of characteristic resources is very limited.

Lacking of Long-term Effective and Quality Management System. The management system is not perfect. The funds investment lacks of long-term effective, The performance of the resource is not rich enough, resource construction responsibility is not clear, resource management is scattered over the time. The lack of necessary resources about audited mechanism, Universities is far from paying attention with the team of setting up resources, lacking of the technical. There is no incentive mechanism to guarantee the construction of the long-term effective.

Lacking of Communication Function of the Resource Construction. At present, the problems in the construction of characteristic educational resource are the function of communication. Educational resource provide quality educational resources for teachers and students. The library also provides a good exchange platform for teachers and teachers, teachers and students as well as students and students.

\section{The Construction Strategy of the Characteristic Educational Resource in Ethnic Regions}

The construction and sharing of characteristic educational resources plays positive effect in promoting the innovation of educational mode, learning mode and the mode of talents training and promoting the reform of higher education. The goal of building characteristic educational resource is to provide support for the educational reform and the transformation of the educational mode. Therefore, the development of the design a resource management, courses display, teacher preparation courses and students learning and communicate and other functions will play the educational software platform. The students provide open online course learning environment. The contents of educational resources mainly include professional resources, curriculum resources and professional resources. The different educational resources design may not the same. The main body of the construction of the professional resource is in the colleges. The professional teachers should design resources, arrange data and collection of knowledge point. Therefore, it is necessary to standardize the construction of the resource pool and unified standard. Curriculum resources is an important part of the professional resources, the construction of curriculum resources is a reasonable classification. Common classification methods are classified according to the professional 
classification according to grade. The generals is to the use of tree classification method, divided into the class classification, etc. The mastic resources can be divided into the active and thematic learning resources. The activities of the special resources is the school's propaganda pictures. The subject-based learning resource refers to a particular subject of learning resources, including teacher lectures, expert forum, mainly is through a special website to establish learning and communication platform.

\section{Conclusion and Implications}

The characteristic Educational resource is an important part of the construction of educational system. we use the advantages of modern information technology to make the characteristic educational resources to digital processing and to achieve the sharing of internet. At the same time, it is important to stimulate students to discuss and study independently, and encourage teachers to change their ideas and methods of reform. This has a very important role in deepening the reform of ethnic education, realizing the modernization of education and promoting the quality education in ethnic regions. Each ethnic region can combine the characteristics of the school, develop innovative educational resources, and improve the uniqueness of the construction about resources.

\section{Acknowledgement}

This research was financially supported by the Planning Fund Program of Philosophy and Social Science in Gansu (No: YB017).

\section{References}

[1] Deng Yongfu. The necessity and method of building the special database construction of University database. Journal of Qujing Normal University, 23(2004) 61-68

[2] Jin Lin. On the construction of characteristic database. Journal of Zhengzhou College of Animal Husbandry Engineering, 29 (2009) 121-130

[3] Lang Hanwei. Sharing of database construction engineering characteristics. Science and technology information development and economy, 19 (2012) 90-101

[4] Ma Hongwei. Thoughts on the construction of characteristic database of University Library. Chinese Science \& Technology Expo, (2008)

[5] Outline of national medium and long term education reform and development plan. (2010-2020)

[6] Song Peilin, Zhang Yongjun.. New exploration on the construction of characteristic database of Local University Library. Jiangxi Library Journal, 39 (2009)

[7] Tang Zhenghua. Study on the principle of building college self built database. Library work study, 19 (2009)

[8] Tu Baojun, Sun Jin, Ji Shunyu. Research on the construction mode of educational resources in Applied Undergraduate Colleges. Study on field audio visual education, 04 (2013)

[9] Wang Feng. Discussion on self built database of Digital Library. Scientific and technological information, 4(2008)76-84

[10] Yuan Hua. Intellectual property protection in the construction of Digital Information Resources. Journal of Shanghai Jiao Tong University, (2003) 
[11]Zhu Daoyong. Research on construction technology of characteristic database in University. Inner Mongolia science and technology and economy, (5) (2009) 